\title{
GESTÃO COMERCIAL: ANÁLISE DA ESTRUTURA ORGANIZACIONAL DE UMA COOPERATIVA DE TRABALHADORES EM MATERIAIS RECICLÁVEIS
}

\author{
Edilene M. M. Takenaka, Yeda Ruiz Maria, Gilmara Santos Lima, Graciele Oliveira, Paulo Cesar \\ Ferreira
}

Mestrado em Meio Ambiente e Desenvolvimento Regional - UNOESTE. Curso Superior de Tecnologia em Gestão Comercial - UNOESTE. E-mail: edilene@unoeste.br

\section{RESUMO}

O cooperativismo é formado por uma doutrina econômica estruturada para a geração de riquezas através da união de pessoas que espontaneamente concordam em criar uma cooperativa em determinado segmento produtivo. O objeto de estudo foi a COOPERLIX, uma cooperativa de trabalhadores de coleta e comercialização de resíduos sólidos no município de Presidente Prudente-SP que enfrenta questões conflitantes entre a essência do cooperativismo e a moderna gestão das empresas. $O$ objetivo da presente pesquisa foi de analisar a estrutura organizacional da COOPERLIX buscando otimizar sua produtividade. A fim de propiciar uma melhor abordagem do tema proposto, utilizamos a pesquisa descritiva qualiquantitativa e a técnica de estudo de caso. Iniciamos com a adoção de uma pesquisa bibliográfica sobre o tema abordado e, em seguida, partimos para a aplicação de questionários aos profissionais catadores membros da cooperativa analisada para, a partir dos dados coletados, oferecer propostas de otimização das atividades dos cooperados.

Palavras-chave: Cooperativa. Coleta seletiva. Resíduos sólidos. Gestão organizacional.

\section{INTRODUÇÃO}

Coleta seletiva é um sistema de recolhimento de materiais recicláveis como: papéis, plásticos, vidros, metais e orgânicos, previamente separados na fonte geradora, ou seja, nas casas, nas escolas, ou em empresas, e que podem ser reutilizados ou reciclados. Esta coleta funciona também como um processo de educação ambiental na medida em que sensibiliza a população sobre os problemas do desperdício de recursos naturais e da poluição causada pelo lixo.

Reciclagem é o processo de transformação de um material que já foi utilizado, em outro produto que poderá ser utilizado novamente gerando economia de matéria-prima, reduzindo índices de resíduos poluidores e ampliando a vida útil dos recursos produtivos.

No contexto atual, a reciclagem é imprescindível, pois torna o mercado altamente expansivo e responsável por uma demanda gigantesca. Dessa forma, as oportunidades ainda são crescentes e proporcionam um ótimo ambiente para se investir, levando em conta a sustentabilidade em alta, a escassez de recursos naturais, e ainda o acúmulo de agentes poluentes em todo o planeta.

Segundo uma pesquisa elaborada pelo IBGE (Instituto Brasileiro de Geografia e Estatística) 
nota-se que houve um aumento considerado de 7,7\% na quantidade de RSU coletados em 2010 comparados com o total em 2009 registrando uma média de 230 mil toneladas de lixo diariamente, a região Sudeste do Brasil destaca-se com a maior parte, 53,1\% de produção.

Com a prosperidade econômica o Brasil automaticamente vem se tornando um grande produtor de resíduos sólidos urbanos. A produção brasileira pode variar diariamente entre 0,5 a 1 quilo por pessoa sendo que, quanto maior o poder aquisitivo da população maior é a quantidade de resíduos gerados. A coleta seletiva é um sistema de recolhimento cujo objetivo funciona como um processo de educação ambiental; sensibiliza a população sobre os problemas do desperdício de recursos naturais e também sobre poluição causada pelos resíduos gerados.

O município de Presidente Prudente, localizado no extremo oeste do Estado de São Paulo, possui aproximadamente 209000 mil habitantes e conta com um serviço de coleta de resíduos sólidos, e disposição final feita em local considerado aterro controlado pela prefeitura municipal. Este serviço é prestado por uma empresa de economia mista (PRUDENCO) contratada pela Prefeitura Municipal.

A partir de 2003, com a implantação do Projeto de Políticas Públicas sobre "Educação Ambiental e gerenciamento integrado dos resíduos sólidos em Presidente Prudente SP: Desenvolvimento de metodologias para a coleta seletiva, beneficiamento do lixo e organização do trabalho" financiado pela FAPESP - Fundação de Amparo à Pesquisa do Estado de São Paulo ocorreram diversas parcerias entre: universidades, entidades, sociedade civil e poder público municipal em prol da constituição de uma cooperativa de catadores de materiais recicláveis com o intuito de iniciar a coleta seletiva no município e contribuir para a educação ambiental. (TAKENAKA, 2008)

No dia 14 de Abril de 2010, o lixão da cidade de Presidente Prudente foi fechado definitivamente em cumprimento ao Termo de Ajustamento de Conduta (TAC), todos os catadores tiveram que deixar o lugar, e para minimizar o impacto causado nestas famílias, várias reuniões foram efetuadas com o objetivo de amparar os catadores que permaneciam no local. A prefeitura municipal, através de seus representantes, propôs a contratação temporária deste pessoal e futuro encaminhamento a todos os que aceitassem as regras do estatuto da Cooperlix, à integração ao quadro da cooperativa.

A Cooperlix (Cooperativa de trabalhadores de produtos recicláveis de Presidente Prudente) foi fundada em 2003, porém foi a partir de abril de 2010 que suas atividades ficaram mais 
evidenciadas no município devido ao apoio obtido de varias instituições educacionais, particulares e públicas do município de Presidente Prudente/SP. (TAKENAKA, 2008)

Segundo OLIVEIRA (2011) o cooperativismo é formado por uma doutrina econômica estruturada para a geração de riquezas através do livre associativismo entre pessoas que espontaneamente concordam em criar uma cooperativa em qualquer segmento produtivo permitido pela legislação.

Com isto entendemos que o cooperativismo busca tanto satisfazer suas necessidades financeiras e realização pessoal/profissional através da produtividade e da valorização humana e não da exploração do homem pelo homem.

Segundo ARANA (2006), cooperativa é uma sociedade de pessoas e não somente de capital, organizada segundo certos princípios, que podem ser sintetizados em: propriedade, gestão e repartição cooperativa.

A palavra cooperativismo não é apropriada para designar o conjunto e cooperativas, o termo adequado é sistema cooperativista ou movimento cooperativista destinado ao conjunto de cooperativas e as instituições a elas ligadas. A palavra cooperativa se refere ao empreendimento que atua no mercado em nome dos associados. (IRION, p.45, 1997)

Pode-se interpretar que a COOPERLIX surge como alternativa de obtenção de emprego e renda para a sobrevivência financeira dos cooperados, por isto a importância da reestruturação e do desenvolvimento de soluções adequadas para acompanhar a evolução de novas tecnologias.

Tratando-se de uma cooperativa, o principal elemento aglutinador é a potencialidade de se estabelecer normas, objetivando cumprir o papel para o gerenciamento integrado de resíduos sólidos, visando obter melhorias na produção e remuneração dos cooperados.

Procuramos, através da presente pesquisa, analisar a estrutura organizacional da COOPERLIX buscando compreender o entendimento dos seus membros sobre a gestão cooperativa realizada.

\subsection{Metodologia da pesquisa}

Para a realização do presente trabalho adotamos o método dedutivo no qual o método científico parte de um problema que, em geral, surge a partir de um conflito frente às expectativas ou conhecimento prévio, através de análise de dados técnicos gerais relativos ao tema. Iniciamos a presente pesquisa com o levantamento de dados a partir da documentação indireta em fontes primárias e secundárias. 
As fundamentações teóricas foram necessárias para a compreensão dos fenômenos estudados.

A pesquisa bibliográfica, segundo Gil (2002) e Lakatos \& Marconi (1985), tem por finalidade posicionar o pesquisador com o que já foi anteriormente escrito sobre determinado tema, com o objetivo de permitir o esforço paralelo na análise de suas pesquisas ou manipulação de suas informações.

Em seguida, realizamos a coleta de dados através de uma pesquisa exploratória com a aplicação de um questionário e entrevistas junto a alguns membros cooperados.

Cabe destacar que foram realizadas entrevistas e aplicação de questionários para um grupo de 22 membros cooperados da COOPERLIX cujo procedimento foi aprovado pela Coordenadoria Central de Pesquisa (CCPq) e seus comitês de apoio ao desenvolvimento da pesquisa: CAPI (Comitê Assessor de Pesquisa Institucional) e CEP (Comitê de Ética em Pesquisa). (Protocolo 1136/2012).

Efetuadas as etapas de pesquisa propostas, analisamos os resultados obtidos com o objetivo de definir alguns aspectos relevantes estabelecendo uma conclusão referente ao tema proposto.

\section{COOPERATIVISMO E SEUS FUNDAMENTOS}

O cooperativismo é a junção do desenvolvimento econômico e bem estar social fundamentado na reunião de pessoas, visando as necessidades do grupo e não do lucro.

O timbre que representa as cooperativas é de um círculo e dois pinheiros, que tem um significado muito interessante: os pinheiros representam a união e a fraternidade, o verde-escuro dos pinheiros simboliza o principio vital da natureza, já o círculo é uma figura que não tem começo nem fim, e simboliza a eternidade do cooperativismo.

Toda a forma organizada de gestão incluindo uma cooperativa deve apresentar uma estrutura sólida e bem dividida. Cada uma das pessoas interessadas na participação em um empreendimento como este deve conhecer as formas adequadas de seu funcionamento, as determinações legais e todas as características que garantam a condução de ações, da maneira mais harmoniosa possível.

Sendo assim podemos concluir que o cooperativismo é uma forma organizacional em que os cooperados são donos e usuários do próprio negocio. 
Cooperativas são organizações democráticas controladas por seus sócios que, por sua vez, participam ativamente nas tomadas de decisões. Homens e mulheres eleitos como representante são responsáveis pelo seu funcionamento.

Segundo Arana (2006. p.14):

"A conscientização da população esta vinculada aos aspectos culturais e organizacionais dos próprios cooperados, não é possível educar a população se os próprios cooperados não têm essa conscientização. É necessário antes de iniciar uma campanha com a população treinar os cooperados para esclarecer as dúvidas e divulgar o projeto."

De acordo com esta citação percebemos que a grande dificuldade da Cooperlix é a dependência dos cooperados por ajuda de terceiros, ou seja, eles não tomam iniciativa face aos problemas da cooperativa, sendo de suma importância a presença permanente de um responsável pela gestão.

\subsection{Estrutura da COOPERLIX}

Conforme o Estatuto da Cooperativa dos Trabalhadores de Produtos Recicláveis de Presidente Prudente, a Cooperlix tem por objetivo a defesa sócio-econômica dos seus associados através da organização do trabalho individual e tratando seus interesses junto a terceiros na área de prestação de serviços, entre outros, de: coleta seletiva de materiais recicláveis, além de sua armazenagem, distribuição e venda.

A cooperativa é administrada por um Conselho de Administração, que é formado por 6 membros efetivos e 3 vogais, compondo a diretora executiva (Presidente, Vice-presidente, 1으 e 2은 Secretário, e 1ㅇ e 20 Tesoureiro) esta diretoria será exclusivamente composta por associados eleitos pela assembleia geral que exercerá o mandato de dois anos, sendo obrigatória a renovação de no mínimo um terço dos seus componentes após este prazo. No caso de ausência ou impedimentos dentro de um prazo máximo de 90 dias de qualquer membro efetivo, o mesmo será substituído por outro cooperado.

\section{RESULTADOS}

Para analisar o processo de funcionamento da Cooperlix, foi elaborado um questionário onde entrevistamos 22 cooperados sendo eles, 9 homens e 13 mulheres com idade entre 22 e 70 anos, entre todos os entrevistados, somente 2 não tem filhos porém possuem familiares (pais e irmãos) que dependem da sua renda. 
Dos 22 cooperados, 05 possuem ensino médio incompleto e os outros 17 não concluíram o ensino fundamental e todos possuem uma renda média mensal de 01 salário mínimo.

Os cooperados desconhecem o significado de estrutura organizacional.

Eles relatam que os resíduos não são separados devidamente e o trabalho dos mesmos é dificultado pelo tempo que passam na triagem.

Todos os entrevistados concordam que o roteiro elaborado para a coleta nas ruas não possui um planejamento adequado causando despesas desnecessárias no combustível, no trajeto e na gestão do tempo do percurso.

A maioria dos entrevistados (80\%) acredita que o problema esta na administração da cooperativa, pela falta de gestão e planejamento, outros (20\%) acreditam que a principal causa do problema da COOPERLIX e o absenteísmo na cooperativa.

\section{DISCUSSÃO}

Em pesquisa de campo, acompanhando alguns dias de trabalho na COOPERLIX (junho a novembro/2012), o grupo de pesquisadores identificou uma estrutura física (utilização por regime de comodato com a prefeitura municipal) adequada para o funcionamento da cooperativa composta por área interna coberta em que estão acomodadas as esteiras, as prensas, as balanças e as baias destinadas à separação do material selecionado. Também possui uma sala para escritório, uma cozinha, dois vestiários com banheiros (masculino e feminino) e um refeitório que faz às vezes de sala de reunião sendo que todos os ambientes possuem móveis e equipamentos adequados para a sua utilização.

Para a realização da coleta pelas ruas do município, a COOPERLIX conta com 3 caminhões que se dividem entre os bairros atendidos pelo programa de coleta seletiva.

Importante salientar que os equipamentos e os caminhões utilizados pela COOPERLIX foram obtidos através de um esforço conjunto de diversos setores da sociedade envolvidos em um Projeto de Políticas Públicas sobre “Educação Ambiental e gerenciamento integrado dos resíduos sólidos em Presidente Prudente SP: Desenvolvimento de metodologias para a coleta seletiva, beneficiamento do lixo e organização do trabalho" (Projeto de Políticas Públicas/FAPESP), realizado em parceria pela Faculdade de Ciências e Tecnologia (FCT/UNESP), Universidade do Oeste Paulista (UNOESTE), Prefeitura Municipal de Presidente Prudente, Companhia Prudentina de Desenvolvimento (PRUDENCO), Fundo Social de Solidariedade, Federação Nacional dos Trabalhadores em Serviços, Asseio e Conservação, Limpeza Urbana, Ambiental e Áreas Verdes 
(FENASCON) e Sindicato dos Empregados em Empresas de Asseio e Conservação e Trabalhadores na Limpeza Urbana de Presidente Prudente e Região (SIEMACO), com apoio da Fundação de Amparo à Pesquisa do Estado de São Paulo (FAPESP), Núcleo 3R da Universidade Federal de São Carlos.

Observamos também que, a quantidade de material reciclável coletada fica um tempo muito grande aguardando a etapa da seleção de materiais.

Por fim, constatamos que os principais problemas identificados junto aos cooperados pesquisados referem-se à falta de um planejamento logístico estrutural e de uma gestão administrativa, uma vez que os entrevistados disseram desconhecer o significado de estrutura organizacional.

Há uma percepção da maioria entrevistada sobre falhas no processo de triagem e separação de materiais recicláveis e também no roteiro para a coleta dos materiais nos bairros do município.

Uma parcela dos entrevistados afirmou que grande parte dos cooperados trabalha desmotivada devido aos baixos ganhos e também pela falta de comprometimento de alguns colegas na realização das atividades cooperadas necessárias e nas constantes ausências nos dias de trabalho.

\section{CONCLUSÃO}

A redução do lixo gerado pela população, como a reutilização de materiais descartados e a reciclagem dos materiais que possam servir de matéria prima para a indústria, diminuindo o desperdício e gerando renda, são conquistas da implantação da gestão dos resíduos sólidos, a qual busca mais sustentabilidade ambiental e social.

Observa-se que os catadores de materiais recicláveis prestam um serviço essencial para a sociedade. No entanto, apesar de constituírem um dos elos principais da cadeia produtiva da reciclagem, são, também, o elo mais frágil, encontrando-se extremamente marginalizados, na maioria das cidades.

Pode-se pontuar que o apoio do poder público aos catadores, seja na forma de campanhas educativas, ou de infra-estrutura. Observando que não se trata de uma política assistencial, e sim, de reconhecimento da sua importância para o gerenciamento dos resíduos sólidos, com o estabelecimento de parcerias entre governo e trabalhadores, em prol de objetivos comuns, como a preservação dos recursos naturais, a diminuição dos custos com a coleta regular do lixo e 
operação de aterros sanitários, a educação ambiental e o desenvolvimento local e mais sustentável.

A forma de organização dos trabalhadores na coleta e triagem do material depende da realidade do município. No caso de Presidente Prudente já existiam catadores vivendo do lixo, o ideal foi a integração desses trabalhadores no programa de coleta seletiva, incentivando e apoiando sua organização em cooperativas de catadores.

A função da cooperativa é a de coletar, separar, prensar e comercializar os materiais. A COOPERLIX apenas separa e comercializa os materiais coletados nos bairros do município. Entretanto o importante é que os catadores sejam valorizados, através de treinamentos, capacitações e programas de inclusão social, de maneira que alcancem, em médio prazo, a autogestão de suas organizações.

Por fim, sugere-se, para os futuros trabalhos uma reorganização na estrutura organizacional da Cooperlix redefinindo um planejamento adequado tanto nos trajetos da coleta seletiva quanto a implantação de um sistema gerencial interno abrindo novas vagas para a entrada novos membros e atividades motivacionais para os cooperados.

\section{REFERÊNCIAS}

ARANA, A. R. A. Cooperativismo uma alternativa de gestão. Editora Macromidia Ltda 10 Edição, 2006.

GIL. A C. Como elaborar projetos de pesquisa. São Paulo:Atlas, 2002

IRION, J. E. Cooperativismo e economia social. São Paulo: STS, 1997.

LAKATOS, E M \& MARCONI, M A. Fundamentos de metodologia científica. São Paulo:Atlas, 1985

OLIVEIRA, D. P. R. Manual de gestão das Cooperativas. Editora Atlas 5o Edição. São Paulo, 2011

TAKENAKA, E. M. M. Políticas públicas de gerenciamento integrado de resíduos sólidos urbanos no município de Presidente Prudente-SP, Presidente Prudente: FCT, UNESP, 2008, f. Tese (Doutorado) - Faculdade de Ciências e Tecnologia, Universidade Estadual Paulista, 2008. 